\title{
Catabolism of L-Arginine by Pseudomonas aeruginosa
}

\author{
By ANNICK MERCENIER, ${ }^{1 *}$ JEAN-PAUL SIMON, ${ }^{1}$ DIETER HAAS ${ }^{2}$ \\ AND VICTOR STALON ${ }^{1}$ \\ ${ }^{1}$ Laboratoire de Microbiologie, Faculté des Sciences, Université Libre de Bruxelles and \\ Institut de Recherches du C.E.R.I.A., Avenue Emile Gryzon 1, B-1070 Brussels, Belgium \\ ${ }^{2}$ Mikrobiologisches Institut, E.T.H. Zürich, Universitätstrasse 2, CH-8006 Zürich, \\ Switzerland
}

(Received 12 July 1979)

\begin{abstract}
Pseudomonas aeruginosa is known to break down arginine by the arginine deiminase pathway. An additional pathway has now been found whereby arginine is converted to putrescine with agmatine and $N$-carbamoylputrescine as intermediates. The following enzyme activities belonging to this pathway were detected in crude extracts: arginine decarboxylase (EC 4.1.1.19), which catalyses the release of $\mathrm{CO}_{2}$ from arginine to give agmatine; agmatine deiminase (EC 3.5.3.12), which degrades agmatine to $N$-carbamoylputrescine; and $N$ carbamoylputrescine amidinohydrolase (EC 3.5.3.-), which then removes the ureido group of carbamoylputrescine. In crude extracts, arginine decarboxylase activity was stimulated by pyridoxal phosphate, $\mathrm{Mg}^{2+}$ and by the products of the catabolic pathway, putrescine and spermidine.

Growth of $P$. aeruginosa on arginine as the sole carbon and nitrogen source markedly increased the activity of arginine decarboxylase. Agmatine and $N$-carbamoylputrescine induced the synthesis of agmatine deiminase and $\mathrm{N}$-carbamoylputrescine hydrolase. Addition of succinate or citrate to medium containing arginine or agmatine led to repression of the enzymes involved in the arginine decarboxylase pathway. Moreover, the repression of agmatine deiminase and $N$-carbamoylputrescine hydrolase was further increased when $P$. aeruginosa was grown in media with agmatine plus glutamine or agmatine plus succinate and ammonia. This suggests that the expression of the agmatine pathway may be regulated by carbon catabolite repression as well as nitrogen catabolite repression.
\end{abstract}

\section{INTRODUCTION}

Fluorescent pseudomonads possess the arginine deiminase pathway (Slade et al., 1954; Stalon et al., 1967) for the catabolism of arginine. This pathway leads to the formation of ATP by the combined action of arginine deiminase, catabolic ornithine carbamoyltransferase and carbamate kinase (Stalon et al., 1967, 1972). The deiminase pathway is also a source of energy for fermentative organisms like Clostridium (Mitruka \& Costilow, 1967) and Streptococcus faecalis (Bauchop \& Elsden, 1960).

In Bacillus licheniformis, arginase converts arginine to ornithine in well-aerated cultures, whereas the arginine deiminase pathway is induced in anaerobiosis (Broman et al., 1975, 1978). A mutant of $B$. licheniformis displaying a 10-fold decreased level of carbamate kinase activity was unable to grow anaerobically on pyruvate plus arginine, but grew well aerobically on the same medium (K. Broman, unpublished results). This observation indicates that the arginine deiminase pathway can be an energy source in Bacillus growing anaerobically.

In pseudomonads, the enzymes involved in the arginine deiminase pathway have their highest activities in organisms deprived of oxygen (Haas et al., 1979; Halleux et al., 1972). A recently isolated mutant of $P$. aeruginosa lacking catabolic ornithine carbamoyltransfer- 
ase (Haas et al., 1979) grew aerobically on arginine as the only carbon and nitrogen source at the same rate as the wild-type. The properties of the mutant demonstrate that there must be at least one other arginine catabolic pathway in this organism. Kay \& Gronlund (1969) showed that putrescine is a product of arginine catabolism by intact $P$. aeruginosa. Two modes of putrescine formation were considered: (i) arginine could be degraded via the arginine deiminase pathway to give ornithine, which would then be decarboxylated (Morris \& Pardee, 1966); (ii) arginine could be degraded to putrescine via agmatine, without ornithine as an intermediate. In Escherichia coli, arginine can be decarboxylated to give agmatine and the direct conversion of agmatine to putrescine is catalysed by agmatine ureohydrolase (Morris \& Pardee, 1966). In Streptococcus faecalis, agmatine induces an agmatine deiminase which produces $N$-carbamoylputrescine, and a catabolic putrescine carbamoyltransferase then catalyses the formation of putrescine and carbamoylphosphate (Roon \& Barker, 1972; B. Wargnies, N. Lauwers \& V. Stalon, unpublished observations). In higher plants, carbamoylputrescine is degraded by an $N$-carbamoylputrescine amidinohydrolase (Smith \& Garraway, 1964; Smith, 1965).

In this paper, we show that in $P$. aeruginosa arginine can be converted to putrescine via two intermediates, agmatine and $N$-carbamoylputrescine. We have also examined the regulation of the two arginine catabolic pathways in this organism. A preliminary report of these results has been published (Mercenier et al., 1978).

\section{METHODS}

Bacterial strains and growth of organisms. Pseudomonas aeruginosa wild-type strain PAO1 (ATCC 15692) and mutant strain PAO630 ( $\operatorname{argF2}$, arcB9) (Haas et al., 1979) were used. These strains were routinely grown at $37^{\circ} \mathrm{C}$ on minimal medium $\mathrm{P}$, a nitrogen-free salts medium (Leisinger et al., 1972). Carbon and nitrogen sources were added (each at $20 \mathrm{~mm}$ ) after sterilization by autoclaving, except for agmatine, glutamine, $N$-carbamoylputrescine and putrescine which were sterilized by filtration. Cultures were grown in flasks fitted with side-arms on a rotary shaker. The volume of the culture fluid was $10 \%$ of the flask volume. Cells from exponential phase cultures (about $4 \times 10^{8}$ cells $\mathrm{ml}^{-1}$ ) were harvested by centrifuging, washed with $0.9 \%(\mathrm{w} / \mathrm{v}) \mathrm{NaCl}$ at $0{ }^{\circ} \mathrm{C}$ and, if not used immediately, they were stored frozen as a pellet.

Preparation of cell extracts. Extracts were prepared by suspending the cells in $2 \mathrm{ml} 50 \mathrm{~mm}$-phosphate buffer $\mathrm{pH} 7.5$ supplemented with $0.5 \mathrm{~mm}$-dithiothreitol and $5 \%(\mathrm{v} / \mathrm{v})$ ethyleneglycol, subjecting the suspensions to $5 \mathrm{~min}$ disruption in a Mullard Sonic Oscillator and removing cell debris by centrifuging at $20000 \mathrm{~g}$ for $10 \mathrm{~min}$ at $4{ }^{\circ} \mathrm{C}$.

Synthesis of $N$-carbamoylputrescine. $N$-Carbamoylputrescine was synthesized from putrescine and cyanate as described by Smith \& Garraway (1964) with some modifications. After precipitation twice with ethanol acidified with conc. $\mathrm{HCl}(1 \%, \mathrm{v} / \mathrm{v})$, the preparation of $N$-carbamoylputrescine was still contaminated with putrescine and $N, N^{\prime}$-dicarbamoylputrescine. The white precipitate was dissolved in water and chromatographed on a Dowex 50W-X2 column $\left(\mathrm{H}^{+}\right.$form, in water). $N, N^{\prime}$-Dicarbamoylputrescine was eluted immediately, $N$-carbamoylputrescine by a linear gradient of $\mathrm{KCl}$ from 0 to $1.5 \mathrm{M}$, and putrescine with $2 \mathrm{M}-\mathrm{KCl}$. The pooled fractions of $N$-carbamoylputrescine were at least $99 \%$ pure and stored at $-20{ }^{\circ} \mathrm{C}$ after acidification to $\mathrm{pH} 4$ with $\mathrm{HCl}$.

The enzymic synthesis of $N$-[carbamoyl $\left.-{ }^{14} \mathrm{C}\right]$ carbamoylputrescine was accomplished under the following conditions. The reaction vessel contained (in $2 \mathrm{ml}$ ) $10 \mu \mathrm{mol}$ putrescine, $6.5 \mu \mathrm{mol}\left[{ }^{14} \mathrm{C}\right]$ carbamoylphosphate (total radioactivity $50 \mu \mathrm{Ci}, 1.85 \mathrm{GBq}$ ) and $40 \mu \mathrm{g}$ purified putrescine carbamoyltransferase of Streptococcus faecalis. After incubation at $37^{\circ} \mathrm{C}$ for $30 \mathrm{~min}$, the reaction was stopped by boiling for $10 \mathrm{~min}$ to destroy the excess carbamoylphosphate and ${ }^{14} \mathrm{CO}_{2}$ was removed by bubbling air through the solution.

Separation of intermediates of arginine catabolism. The procedure used was based on that described by Moore et al. (1958), but several modifications were made to allow the identification of products related to arginine catabolism. A typical elution pattern of a mixture of various amino acids, guanidino compounds and polyamines from the cationic exchange resin Aminex A4 is shown in Fig. 1. Separation was at $73{ }^{\circ} \mathrm{C}$ using stepwise elution on a $0.9 \times 20 \mathrm{~cm}$ column. The first elution was with $0.1 \mathrm{M}$-sodium citrate buffer pH 5.28 for $75 \mathrm{~min}$. After this time, $0.066 \mathrm{M}$-sodium citrate buffer $\mathrm{pH} 6.0$ containing $\mathrm{KCl}$ at $120 \mathrm{~g} \mathrm{l}^{-1}$ (buffer B) was passed through the column as proposed by Gehrke et al. (1977). The flow rate through the column was $120 \mathrm{ml} \mathrm{h}^{-1}$ and the ninhydrin reagent pump delivered $60 \mathrm{ml} \mathrm{h}^{-1}$. The time of the ninhydrin reaction in the coil at $100{ }^{\circ} \mathrm{C}$ was $10 \mathrm{~min}$. For all products tested, the recovery after analysis was $\geqslant 95 \%$. 


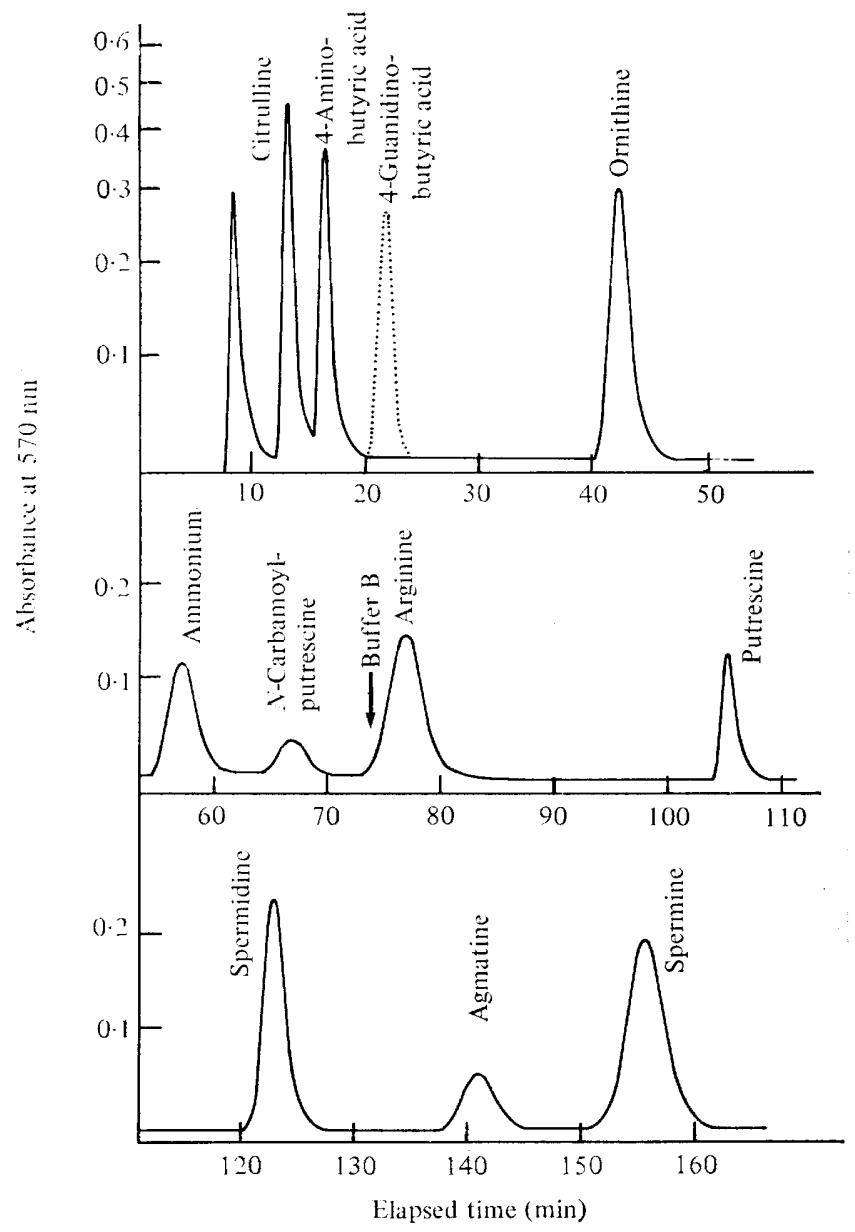

Fig. 1. Ion-exchange chromatography of basic amino acids, amines and diamines. A mixture of $50 \mu \mathrm{mol}$ of each compound was applied to an Aminex A4 column and eluted as described in Methods. Guanidinobutyrate was determined by the method of Sakaguchi as described by Ramos et al. (1970).

Assays of enzyme activities. Enzyme-catalysed decarboxylation was assayed by measuring the liberated ${ }^{14} \mathrm{CO}_{2}$ as previously described (Legrain \& Stalon, 1976).

Arginine decarboxylase (EC 4.1.1.19; L-arginine carboxy-lyase). The standard incubation mixture contained (in $1 \mathrm{ml}$ ) $50 \mu \mathrm{mol}$ Tris $/ \mathrm{HCl}$ buffer $\mathrm{pH} 8 \cdot 25,10 \mu \mathrm{mol}$ putrescine, $5 \mu \mathrm{mol} \mathrm{L}$-arginine and DL$\left[1-{ }^{14} \mathrm{C}\right]$ arginine (40 000 c.p.m. $\mu \mathrm{mol}^{-1}$ ), $0 \cdot 1 \mu \mathrm{mol}$ pyridoxal phosphate, $4 \mu \mathrm{mol} \mathrm{MgCl}_{2}, 0 \cdot 5 \mu \mathrm{mol}$ dithiothreitol and cell extract to attain about $1 \mathrm{mg}$ pretein. The incubation time was 10 to $25 \mathrm{~min}$. The enzyme was labile and rapidly destroyed on freezing whole cells or cell extracts. Activity was conserved for at least $8 \mathrm{~h}$ by the addition of $0.5 \mathrm{~mm}$-dithiothreitol and $5 \%(\mathrm{v} / \mathrm{v})$ ethyleneglycol to the extraction buffer.

$N$-Carbamoylputrescine amidinohydrolase (EC 3.5.3.-). The incubation mixture contained (in $1 \mathrm{ml}$ ) $50 \mu \mathrm{mol}$ EDTA/NaOH buffer pH 7·25, $2 \mu \mathrm{mol} N$-carbamoylputrescine plus $N$-[carbamoyl-14 $\mathrm{C}$ ]carbamoylputrescine ( 35000 c.p.m. $\mu \mathrm{mol}^{-1}$ ) and extract. Enzyme activity was proportional to protein concentration and time for at least $60 \mathrm{~min}$, provided less than $30 \%$ of the substrate was consumed.

Ornithine decarboxylase (EC 4.1.1.17; L-ornithine carboxy-lyase). The incubation mixture contained (in $1 \mathrm{ml}$ ) $50 \mu \mathrm{mol}$ EDTA/ NaOH buffer $\mathrm{pH} 7 \cdot 0,0 \cdot 025 \mu \mathrm{mol}$ pyridoxal phosphate, $0 \cdot 1 \mu \mathrm{mol}$ L-ornithine plus DL- $\left[1{ }^{14}\right.$ C $]$ ornithine $\left(2 \times 10^{6}\right.$ c.p.m. $\left.\mu \mathrm{mol}^{-1}\right)$ and extract. Enzyme activity was proportional to protein concentration and time up to $30 \%$ substrate consumption.

Agmatine deiminase (EC 3.5.3.12; agmatine iminohydrolase). This enzyme was assayed by colorimetric determination of $N$-carbamoylputrescine. The standard incubation mixture contained (in $2 \mathrm{ml}$ ) $100 \mu \mathrm{mol}$ EDTA/NaOH buffer pH 7.8, $10 \mu \mathrm{mol}$ agmatine and extract. The reaction was started by adding the agma- 
tine solution and stopped after $15 \mathrm{~min}$ by adding $2 \mathrm{ml}$ of $1 \mathrm{M}$-HCl. $\mathrm{N}$-Carbamoylputrescine formed was measured by the method of Archibald (1944). The activity was proportional to enzyme concentration and time at least within the range of 0.05 to $3 \mu \mathrm{mol} N$-carbamoylputrescine formed.

Anabolic ornithine carbamoyltransferase (EC2.1.3.3) was assayed as described previously (Stalon et al., 1972).

The protein content of extracts was determined by the method of Lowry, with bovine serum albumin as a standard.

Specific activity is defined as the amount of enzyme catalysing the formation of $1 \mu$ mol product $\mathrm{h}^{-1}(\mathrm{mg}$ protein) $)^{-1}$.

Chemicals. Amino acids, amines and polyamines were from Sigma. Agmatine sulphate contained about $25 \%$ of putrescine and was used without further purification. $\mathrm{DL}-\left[1-^{14} \mathrm{C}\right]$ arginine. $\mathrm{HCl}$ was purchased from CEA-IRE. L-[U- $\left.{ }^{14} \mathrm{C}\right]$ Arginine. $\mathrm{HCl}$, DL- $\left[1-{ }^{14} \mathrm{C}\right]$ ornithine. $\mathrm{HCl}, \mathrm{L}-\left[\mathrm{U}_{-}{ }^{14} \mathrm{C}\right]$ putrescine. $2 \mathrm{HCl}$ and $\mathrm{L}_{-}\left[\mathrm{U}-{ }_{-14} \mathrm{C}\right]-$ citrulline. $\mathrm{HCl}$ were obtained from The Radiochemical Centre, Amersham.

\section{RESULTS}

\section{Intermediates of arginine degradation}

An extract of the wild-type strain of $P$. aeruginosa grown on arginine as the only carbon and nitrogen source was incubated with $\mathrm{L}-\left[\mathrm{U}-{ }^{14} \mathrm{C}\right]$ arginine at $\mathrm{pH} 8.25$, and the incubation products were separated and identified by automated ion-exchange analysis. Almost $40 \%$ of the initial radioactivity was recovered as putrescine (Table 1). Traces of labelled agmatine, $\mathrm{N}$-carbamoylputrescine, ornithine and citrulline were also found, but no urea was recovered. Added citrulline was not converted to putrescine. With ornithine as the substrate of incubation, only traces of putrescine were found. Furthermore, an extract of the mutant PAO630 (which is devoid of catabolic ornithine carbamoyltransferase activity) converted arginine to putrescine to the same extent as the wild type, when grown under identical conditions. Since citrulline and ornithine appeared not to be intermediates in putrescine formation from arginine, further incubations were carried out in the presence of agmatine. The two main products were $N$-carbamoylputrescine and putrescine (Table 1). With $N$-carbamoylputrescine as substrate, $1 \mu \mathrm{mol}$ putrescine was formed per $\mu \mathrm{mol} N$-carbamoylputrescine (Table 1).

\section{Table 1. Products of the enzymic conversion of arginine in vitro}

Cell extract ( $2 \mathrm{mg}$ protein) of strain PAO1 grown on L-arginine was incubated at $37^{\circ} \mathrm{C}$ for $1 \mathrm{~h}$ in a reaction mixture containing (in $1 \mathrm{ml}$ ) either $5 \mu \mathrm{mol}\left[\mathrm{U}-{ }^{14} \mathrm{C}\right]$ arginine (sp.act. 200000 c.p.m. $\mu \mathrm{mol}^{-1}$ ) or $5 \mu \mathrm{mol}$ agmatine or $5 \mu \mathrm{mol} N$-carbamoylputrescine, $10 \mu \mathrm{mol}$ Tris $/ \mathrm{HCl}$ buffer pH $8 \cdot 25$, $0 \cdot 1 \mu \mathrm{mol}$ pyridoxal phosphate and $4 \mu \mathrm{mol} \mathrm{MgCl}_{2}$. At the end of the incubation, $0 \cdot 1 \mathrm{ml} 40 \%(\mathrm{w} / \mathrm{v})$ trichloroacetic acid was added. The protein was removed by filtration and the supernatant solution was subjected to ion-exchange chromatography as described in Methods. With arginine as the incubation substrate, fractions of $2 \mathrm{ml}$ were collected from the column and arginine, putrescine, $N$-carbamoylputrescine, agmatine and citrulline were measured by determination of radioactivity. With agmatine or $N$-carbamoylputrescine as incubation substrate, agmatine, $N$-carbamoylputrescine and putrescine were determined by the ninhydrin test.

Incubation substrate

(5 $\mu \mathrm{mol}$ )

Arginine

Agmatine

$N$-Carbamoylputrescine
Product ( $\mu \mathrm{mol})$

$\begin{array}{lc}\text { Residual arginine } & 2.5 \\ \text { Agmatine } & 0.025 \\ N \text {-Carbamoylputrescine } & 0.1 \\ \text { Citrulline } & 0.05 \\ \text { Ornithine } & <0.05 \\ \text { Putrescine } & 2.0 \\ \text { Residual agmatine } & 1.55 \\ N \text {-Carbamoylputrescine } & 0.65 \\ \text { Putrescine } & 2.8 \\ \text { Residual } N \text {-carbamoylputrescine } & 1.1 \\ \text { Putrescine } & 3.9\end{array}$




\section{Conversion of $N$-carbamoylputrescine to putrescine}

Extracts of organisms grown on arginine, agmatine or putrescine rapidly decarboxylated $N$-carbamoylputrescine. Maximum activity was observed at $\mathrm{pH} 7 \cdot 2$. The apparent $K_{\mathrm{m}}$ for $N$-carbamolyputrescine was $0 \cdot 3 \mathrm{~mm}$ at $\mathrm{pH} 7 \cdot 25$. Pyridoxal phosphate or the divalent cations $\mathrm{Mg}^{2+}$ or $\mathrm{Mn}^{2+}$ were not required for activity. Putrescine (10 mM) and ammonia (100 mM) had a slight inhibitory effect on enzyme activity, as expected if they are reaction products. Phosphate (5 to $100 \mathrm{~mm}$ ) or arsenate (5 to $100 \mathrm{~mm}$ ) did not stimulate the formation of $\mathrm{CO}_{2}$ from $N$-carbamoylputrescine. Thus, the ureido group of $N$-carbamoylputrescine appeared to be cleaved by an amidinohydrolase, as found in plants (Smith \& Garraway, 1964; Smith, 1965). The products were putrescine, $\mathrm{CO}_{2}$ and $\mathrm{NH}_{3}$. No evidence for phosphorolysis (or arsenolysis) of carbamoylputrescine by a catabolic putrescine carbamoyltransferase (Roon \& Barker, 1972) was found. Since the equilibrium constant of the reaction catalysed by putrescine carbamoyltransferase is in favour of carbamoylputrescine synthesis (Roon \& Barker, 1972), extracts were tested for their ability to condense putrescine with carbamoylphosphate; no reaction occurred. Citrulline, a substrate for the catabolic ornithine carbamoyltransferase, did not inhibit the carbamoylputrescine hydrolase reaction.

\section{Conversion of agmatine to $\mathrm{N}$-carbamoylputrescine}

Extracts of organisms grown on arginine, agmatine or $N$-carbamoylputrescine catalysed the conversion of agmatine to $N$-carbamoylputrescine. This reaction, involving the hydrolysis of a $\mathrm{C}-\mathrm{N}$ bond in the guanidino group of agmatine, is catalysed by an agmatine deiminase. Maximum activity was observed at $\mathrm{pH} 7 \cdot 8$. In contrast, arginine deiminase, which is also present in $P$. aeruginosa, had a $\mathrm{pH}$ optimum of $\mathrm{pH} 5.8$ and was stimulated by $\mathrm{MnCl}_{2}$ in crude extracts (results not shown). The apparent $K_{\mathrm{m}}$ for agmatine was $0.1 \mathrm{~mm}$.

\section{Conversion of arginine to agmatine}

Recently, a constitutive arginine decarboxylase was found in a Pseudomonas species isolated from a stagnant pond (Rosenfeld \& Roberts, 1976). Extracts of P. aeruginosa PAO1 grown on arginine catalysed the release of ${ }^{14} \mathrm{CO}_{2}$ from $\mathrm{DL}-\left[1-{ }^{14} \mathrm{C}\right]$ arginine. The reaction was stimulated by pyridoxal phosphate and $\mathrm{Mg}^{2+}$. Maximum activity was observed at $\mathrm{pH} 8 \cdot 0$. The apparent $K_{\mathrm{m}}$ for arginine was $5 \mathrm{mM}$. Putrescine (10 to $20 \mathrm{~mm}$ ) and spermidine ( 2.5 to $4 \mathrm{~mm}$ ) stimulated the enzyme about fivefold in crude extracts under our assay conditions. The enzyme assay was not linear with time or amount of crude extract added. Since putrescine formed during the course of the reaction would be expected to enhance enzymic activity, and may partially explain the lack of linearity, $10 \mathrm{~mm}$-putrescine was routinely included in the assay mixture. Although complete linearity as a function of time and enzyme concentration was not achieved, specific enzyme activities were reproducible for the standard protein concentration ( 1 to $1.5 \mathrm{mg} \mathrm{ml}^{-1}$ ) used in the assay.

\section{Conversion of ornithine to putrescine}

Ornithine was decarboxylated by extracts of $P$. aeruginosa grown on mineral medium supplemented either with glutamate or with succinate and ammonia. The enzyme required pyridoxal phosphate but not $\mathrm{Mg}^{2+}$. Maximum activity was observed at $\mathrm{pH} 7 \cdot 0$. The apparent $K_{\mathrm{m}}$ for ornithine was $0 \cdot 1 \mathrm{mM}$.

\section{Control of synthesis of enzymes involved in the arginine decarboxylase pathway}

The specific activities of the enzymes involved in the arginine decarboxylase pathway were measured under a variety of growth conditions (Tables 2 and 3). For comparison, ornithine decarboxylase and anabolic ornithine carbamoyltransferase activities were also examined (Table 2). 
Table 2. Activities of L-arginine catabolic enzymes, ornithine decarboxylase and anabolic ornithine carbamoyltransferase in extracts of organisms grown on various carbon and nitrogen sources

Specific activities were determined as described in Methods.

\begin{tabular}{|c|c|c|c|c|c|}
\hline Growth medium & $\begin{array}{c}\text { Arginine } \\
\text { decarb- } \\
\text { oxylase }\end{array}$ & $\begin{array}{l}\text { Agmatine } \\
\text { deiminase }\end{array}$ & $\begin{array}{c}N \text {-Car- } \\
\text { bamoyl- } \\
\text { putrescine } \\
\text { hydrolase }\end{array}$ & $\begin{array}{l}\text { Ornithine } \\
\text { decarb- } \\
\text { oxylase }\end{array}$ & $\begin{array}{l}\text { Anabolic } \\
\text { ornithine } \\
\text { carbamoyl- } \\
\text { transferase }\end{array}$ \\
\hline Succinate $+\mathrm{NH}_{4}{ }^{+}$ & 0.53 & 0.8 & $2 \cdot 2$ & $1 \cdot 0$ & $44 \cdot 0$ \\
\hline Glutamate & 0.5 & $1 \cdot 0$ & $1 \cdot 9$ & $1 \cdot 1$ & $19 \cdot 6$ \\
\hline Ornithine & $2 \cdot 2$ & 0.9 & $2 \cdot 2$ & $0 \cdot 3$ & $4 \cdot 3$ \\
\hline Arginine & $6 \cdot 0$ & $1 \cdot 5$ & $2 \cdot 4$ & $0 \cdot 2$ & $1 \cdot 0$ \\
\hline Agmatine & $0 \cdot 2$ & $35 \cdot 0$ & $22 \cdot 0$ & $0 \cdot 5$ & $24 \cdot 0$ \\
\hline$N$-Carbamoylputrescine & $0 \cdot 2$ & $26 \cdot 0$ & $16 \cdot 7$ & 0.6 & 25 \\
\hline Putrescine & $1 \cdot 4$ & 0.9 & $2 \cdot 5$ & 0.8 & 21 \\
\hline Arginine + Succinate & $1 \cdot 14$ & - & - & 0.7 & $18 \cdot 7$ \\
\hline Arginine + Citrate & $1 \cdot 3$ & - & - & $1 \cdot 0$ & $8 \cdot 5$ \\
\hline Arginine + Agmatine & $1 \cdot 8$ & $26 \cdot 6$ & $14 \cdot 0$ & - & $3 \cdot 1$ \\
\hline Arginine $+\mathrm{NH}_{4}^{+}$ & $5 \cdot 0$ & - & - & - & 0.6 \\
\hline
\end{tabular}

Table 3. Activities of agmatine degrading enzymes in extracts of organisms grown on various carbon and nitrogen sources

Specific activities were determined as described in Methods.

\begin{tabular}{|c|c|c|}
\hline Growth medium & $\begin{array}{l}\text { Agmatine } \\
\text { deiminase }\end{array}$ & $\begin{array}{l}N \text {-Car- } \\
\text { bamoyl- } \\
\text { putrescine } \\
\text { hydrolase }\end{array}$ \\
\hline Agmatine & 35 & 22 \\
\hline Agmatine + Pyruvate & 31 & - \\
\hline Agmatine $+\mathrm{NH}_{4}{ }^{+}$ & $32 \cdot 5$ & 一 \\
\hline Agmatine + Succinate & $17 \cdot 5$ & 12 \\
\hline Agmatine + Citrate & $22 \cdot 5$ & - \\
\hline Agmatine + Glucose & 23 & $11 \cdot 5$ \\
\hline Agmatine + Glutamine & 12 & $8 \cdot 7$ \\
\hline Agmatine + Glutamate & 24 & $14 \cdot 0$ \\
\hline Agmatine + Succinate $+\mathrm{NH}_{4}{ }^{+}$ & $11 \cdot 0$ & $8 \cdot 0$ \\
\hline Agmatine + Citrate $+\mathrm{NH}_{4}^{+}$ & $17 \cdot 0$ & - \\
\hline Agmatine + Succinate + Glutamine & $8 \cdot 7$ & $6 \cdot 0$ \\
\hline
\end{tabular}

Induction. Arginine decarboxylase was strongly induced during growth on arginine as the only carbon and nitrogen source, whereas the activities of agmatine deiminase and $\mathrm{N}$ carbamoylputrescine hydrolase were highest with agmatine and $N$-carbamoylputrescine as growth substrates. The activities of the enzymes involved in the arginine decarboxylase pathway were low in cultures grown on minimal medium (succinate $+\mathrm{NH}_{4}^{+}$), whereas the activities of ornithine decarboxylase and the anabolic ornithine carbamoyltransferase were high under these conditions. These two enzymes were repressed in organisms grown on arginine giving a presumptive anabolic function for ornithine decarboxylase. The same regulatory pattern was observed with ornithine as the growth substrate. Arginine decarboxylase synthesis was stimulated but ornithine decarboxylase and the anabolic ornithine carbamoyltransferase were repressed, presumably because ornithine was transformed to arginine. In addition, it has been demonstrated that with citrate as the carbon source activities of the anabolic ornithine carbamoyltransferase are high (Voellmy \& Leisinger, 1978). This seems equally true for ornithine decarboxylase synthesis (Table 3).

Catabolite repression. Various carbon sources repressed the synthesis of the enzymes involved in the arginine decarboxylase pathway (Tables 2 and 3). Succinate appeared to be 


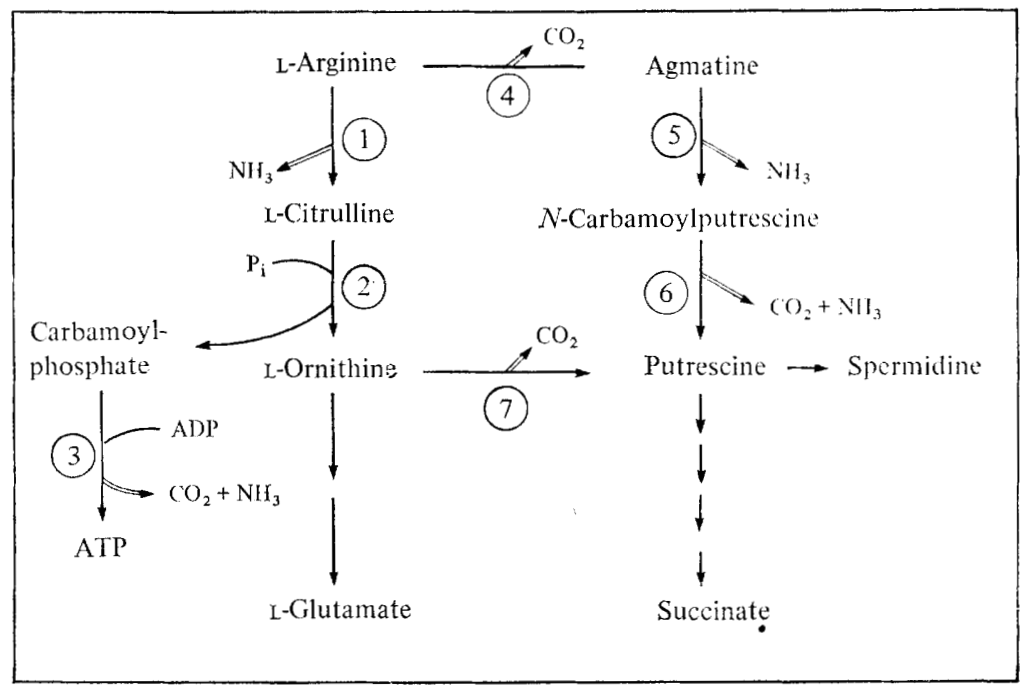

Fig. 2. Pathways of L-arginine catabolism in Pseudomonas aeruginosa: (1) arginine deiminase (EC 3.5.3.6), (2) catabolic ornithine carbamoyltransferase (EC 2.1.3.3), (3) carbamate kinase (EC 2.7.2.2), (4) arginine decarboxylase (EC 4.1.1.19), (5) agmatine deiminase (EC 3.5.3.12), (6) $\mathrm{N}$-carbamoylputrescine amidinohydrolase (EC 3.5.3.-), (7) ornithine decarboxylase (EC 4.1.1.17).

the most effective catabolite repressor. Intermediate activities of the agmatine degrading enzymes were observed when cultures were grown on agmatine plus glucose or citrate. Pyruvate had little effect. In addition to carbon catabolite repression, agmatine deiminase and $N$-carbamoylputrescine hydrolase synthesis were also subject to nitrogen repression by glutamine or ammonia in the presence of succinate. In the absence of a good carbon source, ammonia had little influence, but repression by glutamine occurred even in the absence of succinate.

\section{DISCUSSION}

Pseudomonas aeruginosa has long been known to break down arginine by the arginine deiminase pathway (Thornley, 1960). This paper shows the existence of an additional arginine catabolic pathway which leads to putrescine via agmatine and $N$-carbamoylputrescine (Fig. 2). This pathway was established by two methods: (i) the identification of the intermediates obtained after incubating crude extracts in the presence of arginine, agmatine and $\mathrm{N}$-carbamoylputrescine; (ii) the characterization of the enzyme activities implicated in this pathway.

The arginine decarboxylase catabolic pathway in $P$. aeruginosa is similar to that found in higher plants (Smith \& Garraway, 1964; Smith, 1965) but differs from pathways reported for other bacteria which catabolize arginine by different routes; in particular, E. coli has an agmatine ureohydrolase rather than an agmatine deiminase. In $P$. putida, another arginine catabolic pathway was found by Rodwell and coworkers (Miller \& Rodwell, 1971; Vanderbilt et al., 1975). Here the intermediate products of arginine degradation are 2-oxoarginine, guanidinobutyraldehyde, guanidinobutyrate and 4-aminobutyrate (Miller \& Rodwell, 1971; Vanderbilt et al., 1975). Our attempts to demonstrate such a pathway in $P$. aeruginosa have been unsuccessful. 2-Oxoglutarate, which could be an acceptor of an arginine aminotransferase reaction producing 2-oxoarginine, was without effect on the formation of ${ }^{14} \mathrm{CO}_{2}$ from $\left[1-{ }^{14} \mathrm{C}\right]$ arginine in extracts of strain PAO1 (unpublished observation). No guanidino compounds other than arginine and agmatine were detected under the conditions specified in Table 1. 
In $E$. coli, polyamines act as feedback inhibitors of arginine decarboxylase (Wu \& Morris, 1973); in Pseudomonas, on the other hand, they appeared to be positive effectors of the decarboxylase activity. It is interesting that polyamines are negative effectors of the catabolic ornithine carbamoyltransferase of $P$. putida, which is an allosteric protein (Stalon, 1972) involved in the arginine deiminase pathway.

Maximum induction of arginine decarboxylase occurred with arginine as the sole nitrogen and carbon source. Activity was decreased in the presence of succinate. Ammonia had no effect on the induced synthesis of the decarboxylase, whether or not succinate was present. Agmatine appeared to repress arginine decarboxylase synthesis. Maximum induction of agmatine deiminase and $N$-carbamoylputrescine hydrolase occurred with agmatine as the sole carbon and nitrogen source. In addition to carbon catabolite repression, nitrogen repression also occurred when glutamine or ammonia were added to a medium containing agmatine and succinate. These results suggest that there are at least two regulatory units in the decarboxylase pathway. The first unit is concerned with arginine decarboxylase and the second involves agmatine deiminase and $N$-carbamoylputrescine hydrolase. Our nutritional studies suggest that several systems of catabolite repression operate in the arginine decarboxylase pathway. Whether glutamine synthetase is involved in nitrogen repression (Nyberg \& Clarke, 1978; Potts \& Clarke, 1976) remains to be determined.

The fate of putrescine in $P$. aeruginosa was not studied here. We assume that most of this compound is catabolized to succinate (Voellmy \& Leisinger, 1976). It is probable that some putrescine derived from arginine is also used for spermidine synthesis (Fig. 2). Putrescine can also be formed by ornithine decarboxylase. If the specific enzyme activities measured in vitro (Table 2) reflect the situation in vivo, we may assume that during growth on glutamate or succinate the polyamines are synthesized mainly via the ornithine decarboxylase reaction; during growth on arginine the arginine decarboxylase is expected to prevail in polyamine synthesis.

Pseudomonads are known to possess a great metabolic potential; often there are multiple pathways for the catabolism of one substrate. Three lysine catabolic pathways are known in $P$. aeruginosa (Fothergill \& Guest, 1977). The example of arginine catabolism shows that complex regulatory systems control the biosynthesis (Haas \& Leisinger, 1974) and degradation of a single amino acid.

We thank J. P. ten Have for his skilful assistance in performing the guanidino compounds analysis and E. Rinderknecht for doing preliminary experiments. This work was supported by the Belgian Fonds de la Recherche Fondamentale Collective (grants no. 2.4542.75 and 2.4529.79). D. H. was supported by the Swiss National Foundation for Scientific Research (grant no. 3.204-0.77) and V.S. is chercheur qualifié at the Fonds National de la Recherche Scientifique. A.M. was 'boursière' of the Institut pour l'Encouragement de la Recherche Scientifique dans l'Industrie et l'Agriculture.

\section{REFERENCES}

ARChibald, R. M. (1944). Determination of citrulline and allantoin and demonstration of citrulline in blood plasma. Journal of Biological Chemistry 156, 121-141.

Bauchop, T. \& ElsDen, S. R. (1960). The growth of microorganisms in relation to their energy status. Journal of General Microbiology 23, 457460.

Broman, K., Stalon, V. \& Wiame, J. M. (1975). The duplication of arginine catabolism and the meaning of the two ornithine carbamoyltransferases in Bacillus licheniformis. Biochemical and
Biophysical Research Communications 66, 821827.

Broman, K., Lauwers, N., Stalon, V. \& Wiame, J. M. (1978). Oxygen and nitrate utilization by Bacillus licheniformis of the arginase and arginine deiminase routes of arginine catabolism and other factors affecting their synthesis. Journal of Bacteriology 135, 920-927.

Fothergill, J. C. \& Guest, J. R. (1977). Catabolism of L-lysine by Pseudomonas aeruginosa. Journal of General Microbiology 99, 139-155.

Gehrke, C. W., Kuo, K. C., Ellis, R. L. \& WaAL- 
Kes, T. P. (1977). Polyamines - an improved automated ion-exchange method. Journal of Chromatography 143, 345-361.

HAAS, D. \& LeISINGER, TH. (1974). Multiple control of $N$-acetylglutamate synthetase from Pseudomonas aeruginosa: synergistic inhibition by acetylglutamate and polyamines. Biochemical and Biophysical Research Communications 60, 4247.

Haas, D., Evans, R., Mercenier, A., Simon, J. P. \& Stalon, V. (1979). Genetic and physiological characterization of Pseudomonas aeruginosa mutants affected in the catabolic ornithine carbamoyltransferase. Journal of Bacteriology 139, 713-720.

Halleux, P., Legrain, C., Stalon, V., Piérard, A. \& Wiame, J. M. (1972). Regulation of the catabolic ornithine carbamoyltransferase of Pseudomonas fluorescens. A study of the quaternary structure. European Journal of Biochemistry 31, 386-393.

KaY, W. W. \& Gronlund, A. F. (1969). Amino acid pool formation in Pseudomonas aeruginosa. Journal of Bacteriology 97, 282-291.

Legrain, C. \& Stalon, V. (1976). Ornithine carbamoyltransferase from $E$. coli $\mathrm{W}$ : purification, structure and steady-state kinetic analysis. European Journal of Biochemistry 63, 289-301.

Leisinger, Th., HaAs, D. \& Hegarty, M. P. (1972). Indospicine as an arginine antagonist in Escherichia coli and Pseudomonas aeruginosa. Biochimica et biophysica acta 262, 214-219.

Mercenier, A., Simon, J. P. \& Stalon, V. (1978). Le catabolisme de l'arginine chez Pseudomonas aeruginosa. Archives internationales de physiologie et de biochimie 86, 919-920.

Miller, D. L. \& Rodwell, V. (1971). Metabolism of basic amino acids in Pseudomonas putida. Intermediates in L-arginine catabolism. Journal of Biological Chemistry 246, 5053-5058.

Mitruka, B. M. \& Costilow, R. N. (1967). Arginine catabolism by Clostridium botulinum. Journal of Bacteriology 93, 295-301.

Moore, S., Spackman, D. H. \& Stein, W. H. (1958). Chromatography of amino acids on sulfonate polystyrene resins. Analytical Chemistry 30, 1185-1206.

Morris, D. R. \& Pardee, A. J. (1966). Multiple pathways of putrescine biosynthesis in Escherichia coli. Journal of Biological Chemistry 241, 3129-3135.

NyberG, K. \& Clarke, P. H. (1978). Glutamine synthetase activities of cultures of Pseudomonas aeruginosa grown in minimal media with histidine, nitrate or ammonium sulphate as nitrogen source. Journal of General Microbiology 107, 193-197.

Potts, J. R. \& Clarke, P. H. (1976). The effect of nitrogen limitation on catabolite repression of amidase, histidase and urocanase in Pseudomonas aeruginosa. Journal of General Microbiology 93, 377-387.
Ramos, F., Thuriaux, P., Wiame, J. M. \& Béchet, J. (1970). The participation of ornithine and citrulline in the regulation of arginine metabolism in $S$. cerevisiae. European Journal of Biochemistry 12, 40-47.

Roon, R. J. \& BARKer, H. A. (1972). Fermentation of agmatine in Streptococcus faecalis: occurrence of putrescine transcarbamylase. Journal of Bacteriology 109, 44-50.

RoSENFELD, M. J. \& Roberts, S. (1976). Arginine decarboxylase from Pseudomonas species. Journal of Bacteriology 125, 601-607.

Slade, H. D., Doughty, C. C. \& Slamp, W. C. (1954). The synthesis of high energy phosphate in the citrulline ureidase reaction by soluble enzyme of Pseudomonas. Archives of Biochemistry and Biophysics 48, 333-336.

Smith, T. A. (1965). $N$-Carbamylputrescine amidohydrolase of higher plants and its relation to potassium nutrition. Phytochemistry 4, 599-607.

SMith, T. A. \& Garraway, J. L. (1964). N-Carbamylputrescine - an intermediate in the formation of putrescine by barley. Phytochemistry 3, 23-26.

Stalon, V. (1972). Regulation of the catabolic ornithine carbamoyltransferase of Pseudomonas fluorescens. A study of the allosteric interactions. European Journal of Biochemistry 29, 36-46.

Stalon, V., Ramos, F., Piérard, A. \& Wiame, J. M. (1967). The occurrence of a catabolic and an anabolic ornithine carbamoyltransferase in Pseudomonas. Biochimica et biophysica acta 139, 91-97.

Stalon, V., Ramos, F., Piérard, A. \& Wiame, J. M. (1972). Regulation of the catabolic ornithine carbamoyltransferase of Pseudomonas fluorescens. A comparison with the anabolic transferase and with a mutationally modified catabolic transferase. European Journal of Biochemistry 29, 25-35.

THORNLEY, M. J. (1960). The differentiation of Pseudomonas from other gram-negative bacteria on the basis of arginine metabolism. Journal of Applied Bacteriology 23, 37-52.

VAnderbilt, A. S., Gaby, N.S. \& Rodwell, V. (1975). Intermediates and enzyme between $\alpha$ ketoarginine and guanidinobutyrate in the Larginine catabolic pathway of Pseudomonas putida. Journal of Biological Chemistry 250, $5322-5329$.

Voellmy, R. \& Leisinger, Th. (1976). Role of 4-aminobutyrate aminotransferase in the arginine metabolism of Pseudomonas aeruginosa. Journal of Bacteriology 128, 722-729.

Voellmy, R. \& Leisinger, Th. (1978). Regulation of enzyme synthesis in the arginine biosynthetic pathway of Pseudomonas aeruginosa. Journal of General Microbiology 109, 25-35.

Wu, W. H. \& Morris, D. R. (1973). Biosynthetic arginine decarboxylase from $E$. coli. Purification and properties. Journal of Biological Chemistry 248, 1687-1695. 